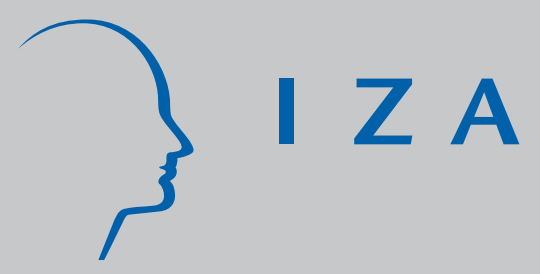

IZADP No. 2211

Performance Related Pay and Labor Productivity

Anne C. Gielen

Marcel J . M. Kerkhofs

J an C. van Ours

July 2006 


\title{
Performance Related Pay and Labor Productivity
}

\author{
Anne C. Gielen \\ Tilburg University, CentER, OSA \\ and IZA Bonn \\ Marcel J.M. Kerkhofs \\ OSA, Tilburg University \\ Jan C. van Ours \\ Tilburg University, CentER, \\ CEPR and IZA Bonn
}

Discussion Paper No. 2211
July 2006

IZA
P.O. Box 7240
53072 Bonn
Germany

Phone: +49-228-3894-0

Fax: +49-228-3894-180

Email: iza@iza.org

\begin{abstract}
Any opinions expressed here are those of the author(s) and not those of the institute. Research disseminated by IZA may include views on policy, but the institute itself takes no institutional policy positions.

The Institute for the Study of Labor (IZA) in Bonn is a local and virtual international research center and a place of communication between science, politics and business. IZA is an independent nonprofit company supported by Deutsche Post World Net. The center is associated with the University of Bonn and offers a stimulating research environment through its research networks, research support, and visitors and doctoral programs. IZA engages in (i) original and internationally competitive research in all fields of labor economics, (ii) development of policy concepts, and (iii) dissemination of research results and concepts to the interested public.
\end{abstract}

IZA Discussion Papers often represent preliminary work and are circulated to encourage discussion. Citation of such a paper should account for its provisional character. A revised version may be available directly from the author. 
IZA Discussion Paper No. 2211

July 2006

\section{ABSTRACT}

\section{Performance Related Pay and Labor Productivity ${ }^{*}$}

This paper uses information from a panel of Dutch firms to investigate the labor productivity effects of performance related pay (PRP). We find that PRP increases labor productivity at the firm level with about $9 \%$ and employment with about $5 \%$.

JEL Classification: $\quad$ C41, H55, J64, J65

Keywords: performance related pay, labor productivity

Corresponding author:

Anne C. Gielen

Department of Economics

Tilburg University

P.O. Box 90153

NL-5000 LE Tilburg

The Netherlands

E-mail: a.c.gielen@uvt.nl 


\section{Introduction}

Performance related pay (PRP) may stimulate labor productivity for two reasons. First, in situations of asymmetric information about worker's abilities or effort a PRP-scheme can be used to induce workers to exert the right amount of effort (see for example Prendergast (1999) and Lazear (2004)). Second, when hiring new workers, piece rates can be used as a screening mechanism to encourage only the most able workers to apply (Lazear, 1986).

PRP-schemes can be either individual performance pay schemes, such as piece rate wages, or collective performance pay schemes, such as profit sharing. In case of teamwork individual performance is difficult to measure, hence there is an incentive to free-ride. In such a case, group-based incentive schemes may have little effect on individual productivity. Additionally, perverse incentives may arise in case of multitasking. When employees are required to perform several tasks, they will focus only on those activities being rewarded and neglecting other activities. Therefore it is not always clear that PRP-schemes indeed increase productivity. Nevertheless, recent empirical studies do find evidence in support of PRP increasing productivity, although the size of the effect differs substantially. Whereas Cahuc and Dormont (1997) for example find a mild increase in productivity due to profit sharing arrangements of about $2 \%$ for French firms, Lazear (2000) finds that piece rates cause productivity to increase with about $40 \%$ for a U.S. firm, half of which is due to an increase of the productivity of the incumbent workforce ("incentive") and half of which is due to the inflow of high-productivity workers ("sorting"). ${ }^{1}$ A similar divi-

\footnotetext{
${ }^{1}$ The empirical literature shows that generally profit sharing arrangement have smaller productivity effects than piece rate schemes. This may have to do with piece rate schemes being applicable
} 
sion of incentive and sorting effects is found in Paarsch and Shearer (2000), where productivity in a Candian firm increases by $22 \%$ after the introduction of PRP.

Over the past decade in the Netherlands the use of performance-related pay (PRP) has increased substantially (Table 1). Whereas in $199530 \%$ of the firms used PRP, this was $39 \%$ in 2001. The increased popularity of PRP-schemes in the Netherlands is not caused by empirical evidence about productivity effects. As far as we know this is the first paper that presents an analysis of the PRP-productivity effects in Dutch firms. In our analysis we account for potential selectivity of PRPadoption, i.e. the case in which more profitable firms are more likely to introduce performance related pay. Our results indicate that PRP indeed increases productivity substantially. The contribution of this paper to the literature is twofold. First, we add to the small number of studies that investigate the productivity effect of PRP using firm level panel data. Second, we investigate the effect of PRP on worker flows at the firm level which apart from some case studies (Lazear, 2000; Paarsch and Shearer, 2000) no other studies have done on an economy-wide scale.

\section{Data}

The OSA Labor Demand Panel is a biennial longitudinal panel survey among establishments with at least 5 employees. ${ }^{2}$ The data we use are from four consecutive waves and cover the period 1995-2001. In our data 794 establishments are observed twice, 288 three times, 84 four times, which gives us a sample of 1166 firms with 2788 observations. The dataset comprises all industries, but the sample is stratified only in situations in which individual output can be monitored and free-riding is not an issue.

${ }^{2}$ In this paper we will use the terms establishment and firm interchangeably to describe the unit of analysis. 
with respect to the area of economic activity and firm size. ${ }^{3}$

For each wave of the panel we know whether or not a PRP scheme is active. Unfortunately, we do not know how many workers in the firm receive PRP. Therefore, our PRP-variable is a dummy variable indicating whether or not performance-related payments occur in the firm. Additionally, the dataset contains information on sales and production costs, which allows the construction of a measure of per capita value added for each establishment. Finally, we have information about the size of worker inflow and outflow on the firm level. Though it would be interesting to also investigate the effects of PRP on wages, unfortunately this cannot be done due to lack of appropriate wage information.

\section{Productivity effects}

\subsection{Determinants of PRP}

Table 1 provides some stylized facts on the presence of PRP. As shown especially larger firms have increased the use of PRP-schemes. Whereas in $199529 \%$ of the firms with more than 100 employees had a PRP-scheme, this increased to $53 \%$ in 2001. Although there is quite some variation in the use of PRP-schemes according to the size of the firm, there is even more variation across industry. Whereas in health care and education only about $10 \%$ of the establishments had a PRP-scheme this is about $55 \%$ in construction.

Estimates on the presence of PRP in firms using our data as a pooled cross section indicate that PRP schemes are more likely to be adopted in large firms and

\footnotetext{
${ }^{3}$ As the OSA panel is a stratified sample with unequal sampling rates, sampling weights are applied to obtain figures that are representative for Dutch establishments with 5 or more employees.
} 
in the construction sector. ${ }^{4}$ In industries where output is difficult to measure, e.g. health care sector, PRP schemes are less likely to be adopted. Furthermore, during the late 1990s the use of PRP schemes has increased.

To correct for potential selection effects, a logit model is estimated accounting for firm fixed effects: $\operatorname{Pr}\left(P_{i t}=1\right)=\Lambda\left(\alpha_{i}+\beta x_{i t}\right)$ and $\operatorname{Pr}\left(P_{i t}=0\right)=\Lambda\left(-\alpha_{i}-\right.$ $\beta x_{i t}$ ), where $P$ indicates whether or not a firm has a PRP scheme, $x$ is a vector of explanatory variables including firm size and calendar year, $\Lambda$ is an indicator of the logistic cumulative distribution function, $i$ refers to firm, $t$ refers to the year $(1995, \ldots, 2001)$ and the $\alpha_{i}$ represent firm fixed effects. Because of the fixed effects many firms characteristics - all non time-varying characteristics - are accounted for. The parameters are estimated using Chamberlain's conditional likelihood method. This means that the parameters are identified on the subset of observations for which the dependent variable changes at least once over time.

The parameter estimates are presented in Table 2 . The results indicate that the effect of firm size is insignificant. Apparently, the firm size effect is more a crosssectional phenomenon than a direct causal effect. There is a clear increase in the use of PRP over time.

\subsection{Labor productivity effects of PRP}

In this section we determine the effect of PRP on labor productivity. Labor productivity is calculated as follows: $y_{i t}=s_{i t} *\left(1-m_{i t}\right) / n_{i t}$, where $s$ represents sales

\footnotetext{
${ }^{4}$ These estimates using a binomial logit model are not presented, but are available on request. In the pooled cross-section estimates we also find that PRP schemes are more likely to be present in firms with a high share of employees covered by a collective agreement and in firms with a high share of white collar workers.
} 
(denoted in 1995 Dutch guilders) ${ }^{5}, m$ the percentage of costs in sales, and $n$ the number of employees of the firm. We estimate the following relationship:

$$
\ln \left(y_{i t}\right)=\gamma_{i}+\gamma_{t}+\beta_{1} \mathrm{P}_{i t}+\beta_{2} \ln \left(e_{i t}\right)+\epsilon_{i t}
$$

where $\gamma_{i}$ represents firm fixed effects, $\gamma_{t}$ represents the calendar time fixed effects, and $e$ represents firm size. Furthermore, the $\beta$ 's are parameters and $\epsilon$ is an error term. We include firm fixed effects in the analysis to control for selectivity in the use of PRP schemes. The parameter estimates are presented in the second column of Table 2. It appears that PRP schemes increase productivity with $9.0 \%{ }^{6}$ Furthermore, firm size has a negative effect on productivity ${ }^{7}$, while firms become more productive over time.

We performed a number of sensitivity analyzes to investigate the robustness of the PRP productivity effect. We started with ignoring the firm fixed effects and did a pooled cross-section analysis, as if we have no panel data. If no panel data are available it is impossible to distinguish between the incentive effects of PRP and spurious correlation between PRP and productivity that will typically arise if more productive firms are more likely to adopt a PRP scheme. As a result of this potential endogeneity of the PRP variable the estimated effect of PRP would be biased upwards. Indeed, as shown in Table 3, in the pooled cross-section the PRPproductivity effect is estimated as $12.4 \% .^{8}$ We also estimated a model in which the

\footnotetext{
${ }^{5}$ For public sector firms, $s$ indicates budget rather than sales.

${ }^{6}$ The results are significant both for private and public sector firms.

${ }^{7}$ The negative effect of firm size in the panel analysis is most likely a short term effect. If firms expand their workforce in the short run productivity goes down.

${ }^{8}$ In these estimates we find that large firms are more productive than small firms. Apparently in the long run productivity are positively correlated with the size of the workforce. These pooled cross-section estimates already control for the spurious correlation caused by differences in the
} 
firm specific effects were included as random effects. This specification implicitly assumes that PRP can be treated as an exogenous variable in the sense that PRPadoption is not related to firm-specific characteristics that are related to higher productivity. As in the pooled regression, the effect of PRP will be overestimated if PRP-adoption is subject to endogenous selection. This expectation is confirmed. Testing the fixed effects specification against the random effects specification, we find that the fixed effects model is to be preferred. ${ }^{9}$

Furthermore, we noticed that there was a lot of variation in the reported sales figures indicating potential measurement errors. In order to reduce measurement errors we excluded observations with a large change in sales between two panel observations. We used an indicator variable $z$ defined as $z_{i t}=\ln \left(s_{i t}\right)-\ln \left(\overline{s_{i}}\right)$ where $\overline{s_{i}}$ is the average sales of firm $i$ over the time period available. First, we remove observations for which $\left|z_{i t}\right|>1$. This reduces the sample size but does not affect the productivity effect of PRP in the fixed effects specification. Applying a more strict criterion of removing observations for which $\left|z_{i t}\right|>0.5$ does not change the results either.

Finally, we re-estimated the model correcting for the average number of working hours in the firm. Hence, we used an indicator of productivity per hour worked. This leads to less accurate estimates for two reasons. First, the information on the working hours is available only for a limited number of firms. Second, the average number of hours is rather imprecise as it is measured in categories. As shown, now

variables that are included in the model. If no variables were included, the productivity difference would even amount to $41 \%$.

${ }^{9}$ The Hausman test of the random effects specification against the fixed effects specification is 100.95. This is a $\chi^{2}$-test with 5 degrees of freedom and firmly rejects the random effects specification indicating that the firm specific effects are correlated with the PRP variable. 
the PRP-parameter is estimated with less precision but, as shown in the bottom line of Table 3, still significantly different from zero at $10 \%$.

All in all, we conclude from our sensitivity analysis that the estimated productivity effect of PRP of $9 \%$ is quite robust.

\section{Worker sorting}

The productivity increase due to PRP that we find in the previous section may be the result of an incentive effect as well as a sorting effect (Lazear, 1986). If worker sorting does occur, we can expect to find an effect of PRP on worker flows as well. In this section we consider the effect of PRP on firm-level worker flows, where we estimate worker inflow and worker outflow simultaneously using a bivariate Tobit model, such that $e_{i t}^{\text {in }}=\max \left[0, e_{i t}^{\text {in*}}\right]$ and $e_{i t}^{\text {out }}=\max \left[0, e_{i t}^{\text {out*}}\right]$, with:

$$
\begin{gathered}
e_{i t}^{\text {in* }}=\gamma_{j}^{\text {in }}+\gamma_{t}^{\text {in }}+\delta_{1} P_{i t}+\delta_{2} P_{i, t-1}+\gamma_{e}^{\text {in }} \ln \left(e_{i t}\right)+\varepsilon_{i t}^{\text {in }} \\
e_{i t}^{\text {out* }}=\gamma_{j}^{\text {out }}+\gamma_{t}^{\text {out }}+\delta_{3} P_{i t}+\delta_{4} P_{i, t-1}+\gamma_{e}^{\text {out }} \ln \left(e_{i t}\right)+\varepsilon_{i t}^{\text {out }}
\end{gathered}
$$

where $e^{\text {in }}$ is the inflow rate and $e^{\text {out }}$ is the outflow rate with the $\delta$ 's as our parameters

of interest. Furthermore the $\gamma_{j}$ 's are fixed effects for industries, the $\gamma_{t}$ 's are fixed effects for calendar years, the $\gamma_{e}$ 's are parameters indicating the effect of firm size and the error terms are assumed to be jointly normally distributed with $\rho=\operatorname{Cov}\left[\varepsilon^{i n}, \varepsilon^{o u t}\right]$. Since we expect worker flows to react gradually to the introduction of PRP, we also include a dummy variable for the presence of PRP lagged one period.

Table 4 presents the estimation results. The results in panel A indicate that worker inflow increases by almost 4 percentage points right after the introduction of 
PRP. In the long run worker inflow is 5 percentage points higher than in firms without PRP. Furthermore, worker outflow increases by more than 1 percentage points initially, and increases in the long run by almost 2 percentage points. However, the parameter estimates for the lagged presence of PRP are insignificantly different from zero. The results in panel B indicate that we cannot reject the hypothesis that the lagged effects are equal to zero. ${ }^{10}$ Because we can ignore lagged PRP-effects our sample size increases substantially. Panel $\mathrm{C}$ shows that in the introduction of PRP increases the inflow with $6.4 \%$ while it increases the outflow with $1.5 \%$. Apparently, the introduction of PRP increases employment growth with almost 5\%. To investigate whether indeed there is permanent employment growth in panel $\mathrm{D}$ we impose the PRP-effects on the inflow and outflow to be of the same size. From a Likelihood Ratio test it appears that we cannot accept the hypothesis that the introduction of PRP does not affect employment growth. ${ }^{11}$

All in all, the results indicate that worker reallocation increases after the introduction of PRP. Unfortunately, we cannot observe whether the average ability of worker inflow differs from that of worker outflow as is predicted by Lazear (1986). ${ }^{12}$

\section{Conclusions}

This paper presents an analysis of the productivity effects of PRP at the firm level. We find that the introduction of PRP increases labor productivity with about $9 \%$. This may be partly due to an incentive effect and partly to selective worker sort-

\footnotetext{
${ }^{10}$ The Likelihood Ratio test statistic equals 0.8 .

${ }^{11}$ The LR test statistic equals 11.4 which is significantly different from zero at a $1 \%$ level.

${ }^{12}$ Note also that if we re-estimate the fixed effects productivity model on the sample of 2112 firms, we find a parameter estimate (standard error) of 0.088 (0.051).
} 
ing. The increase in productivity does not come at a cost of employment. On the contrary: we find a long run employment growth of 5 percentage points.

Our results with respect to the productivity effects of PRP are quite robust. The fixed effects approach proves to be useful for modeling the causal effect of PRP on productivity. To substantiate the estimated effect it would be worth applying the model to data that contain more detailed information about the types of PRP-schemes and the characteristics of workers involved, information that may be available from linked employer-employee data. 


\section{References}

[1] Cahuc, P. and B. Dormont, 1997, Profit sharing: Does it Increase Productivity and Employment? A Theoretical Model and Empirical Evidence on French Micro Data, Labour Economics, 4, 293-319.

[2] Lazear, E.P., 1986, Salaries and Piece Rates, Journal of Business, 59, 405-431.

[3] Lazear, E.P., 2000, Performance Pay and Productivity, American Economic Review, 90, 5, 1346-1361.

[4] Lazear, E.P., 2004, Output-Based Pay: Incentives, Retention or Sorting, in: S.W. Polachek (ed.), Research in Labor Economics, JAI Press, Stanford, 1-25.

[5] Paarsch, H.J. and B. Shearer, 2000, Piece rates, fixed wages, and incentive effects: Statistical evidence from payroll records, International Economic Review, 41, 1, 59-92.

[6] Prendergast, C., 1999, The Provision of Incentives in Firms, Journal of Economic Literature, 37, 7-63. 
Table 1: Presence of performance related pay in Dutch firms $(\%)$

\begin{tabular}{|c|c|c|c|c|c|}
\hline & 1995 & 1997 & 1999 & 2001 & $\begin{array}{l}\text { No. of } \\
\text { firms }\end{array}$ \\
\hline Total & 30 & 35 & 40 & 39 & 2788 \\
\hline \multicolumn{6}{|l|}{ By firm size } \\
\hline$<25$ & 32 & 36 & 40 & 35 & 1037 \\
\hline $25-50$ & 29 & 36 & 33 & 49 & 376 \\
\hline $51-100$ & 21 & 31 & 46 & 48 & 399 \\
\hline$>100$ & 29 & 29 & 40 & 53 & 976 \\
\hline \multicolumn{6}{|l|}{ By industry } \\
\hline Manufacturing, agriculture & 30 & 34 & 38 & 45 & 738 \\
\hline Construction & 44 & 56 & 56 & 55 & 308 \\
\hline Trade & 36 & 36 & 45 & 41 & 255 \\
\hline Transportation & 16 & 14 & 20 & 39 & 83 \\
\hline Financial services & 31 & 42 & 44 & 36 & 242 \\
\hline Health care & 13 & 6 & 7 & 10 & 594 \\
\hline Other services & 21 & 29 & 25 & 35 & 137 \\
\hline Government & 47 & 48 & 40 & 38 & 225 \\
\hline Education & 14 & 8 & 13 & 9 & 206 \\
\hline No. of firms & 763 & 932 & 724 & 369 & 2788 \\
\hline
\end{tabular}

Source: OSA Labor Demand Survey. Sampling weights are used to create numbers that are representative for firm establishments with at least 5 workers. 
Table 2: PRP and productivity

\begin{tabular}{|l|c|c|}
\hline & Presence of PRP & Labor productivity \\
\hline$P$ & - & $0.090(0.042) * *$ \\
$\ln ($ firm size) & $0.397(0.266)$ & $-0.881(0.048) * *$ \\
1997 & $0.128(0.144)$ & $0.130(0.031) * *$ \\
1999 & $0.521(0.181) * *$ & $0.164(0.037) * *$ \\
2001 & $0.688(0.225) * *$ & $0.160(0.048) * *$ \\
\hline Observations & 895 & 2788 \\
Firms & 356 & 1166 \\
\hline
\end{tabular}

Note: Presence of PRP: logit model; Labor productivity: linear regression; all estimates contain firm fixed effects; standard errors in parentheses, a ${ }^{* *}$ indicates that the coefficient is different from zero at a $5 \%$ level of significance; reference year is 1995 . 
Table 3: Sensitivity analysis productivity effects

\begin{tabular}{|l|c|c|}
\hline & PRP parameter & No. of observations \\
\hline Baseline estimate & $0.090(0.042) * *$ & 2788 \\
\hline Pooled cross-section & $0.124(0.044) * *$ & 2788 \\
Random Effects & $0.178(0.039) * *$ & 2788 \\
No outliers $\left(\left|z_{i t}\right|<1\right)$ & $0.089(0.041) * *$ & 2775 \\
No outliers $\left(\left|z_{i t}\right|<0.5\right)$ & $0.091(0.039) * *$ & 2665 \\
Hourly productivity & $0.156(0.088) *$ & 1320 \\
\hline
\end{tabular}

Note: The baseline estimate is similar to the one presented in Table 2; standard errors in parentheses, a ${ }^{* *}(*)$ indicates that the coefficient is different from zero at a $5 \%(10 \%)$ level of significance. 
Table 4: Sorting effects

\begin{tabular}{|c|c|c|c|c|}
\hline & Inflow & Outflow & $\rho$ & -Loglikelihood \\
\hline A. Baseline model & & & & \\
\hline$P_{t}$ & $3.86(1.53) * *$ & $1.24(1.10)$ & - & - \\
\hline$P_{t-1}$ & $1.27(1.52)$ & $0.50(1.09)$ & $0.66(0.02) * *$ & 8783.2 \\
\hline B. Restricted model ${ }^{a)}$ & & & & \\
\hline$P_{t}$ & $4.38(1.40) * *$ & $1.44(1.00)$ & $0.66(0.02) * *$ & 8783.6 \\
\hline Observations & \multicolumn{4}{|c|}{1235} \\
\hline $\begin{array}{l}\text { C. No lagged effects } \\
P_{t} \\
\left.\text { D. Restricted model }{ }^{b}\right)\end{array}$ & $6.39(1.39) * *$ & $1.54(0.69) * *$ & $0.54(0.02) * *$ & 16265.2 \\
\hline$P_{t}$ & $1.25(0.69) * *$ & $1.25(0.69) * *$ & $0.54(0.02) * *$ & 16270.9 \\
\hline Observations & \multicolumn{4}{|c|}{2112} \\
\hline
\end{tabular}

a) Imposing that the lagged PRP-effects equal zero.

b) Imposing that the PRP-effect on the inflow equals the PRP-effect on the outflow.

Note: Worker flows: bivariate Tobit model, other explanatory variables are log of firm size and dummies for calendar year and sector; a ${ }^{* *}$ indicates that the coefficient is different from zero at a $5 \%$ level of significance. 